\title{
GASTOS PÚBLICOS: ANÁLISE DA APLICACÃO DA LEI DE RESPONSABILIDADE FISCAL E DA CONSTITUIÇÃO FEDERAL NO COREDE ALTO JACUÍ
} PUBLIC SPENDINGS: AN ANALYSIS ABOUT THE FISCAL
RESPONSIBILITY LAW AND FEDERAL CONSTITUTION
APPLICATION AT COREDE ALTO JACUI

Data de submissão: $13-08-2013$ Aceite: 14-12-2014

Cristiano Berlt ${ }^{1}$

Reisoli Bender Filho²

Pâmela Amado Tristão ${ }^{3}$

\section{RESUMO}

O planejamento e o controle das contas públicas constituem-se em temas centrais no novo regime de administração pública. Nesse contexto, o presente trabalho objetivou analisar a observância dos limites estabelecidos pela Lei de Responsabilidade Fiscal e pela Constituição Federal nos municípios do COREDE Alto Jacuí, na gestão administrativa 2005-2008. As análises indicaram que a LRF não está sendo cumprida por todos os municípios, visto que em alguns não houve cumprimento ordinário e integral dos limites legais. Ademais, observou-se que o gasto com pessoal cresceu continuamente ao longo do período analisado, sobremaneira em municípios menores populacional e economicamente. Embora se tenha observado o cumprimento dos limites para o financiamento da educação e da saúde em quase a totalidade dos municipíos, constataram-se resultados contrastantes, sendo que municípios com estrutura semelhante apresentaram situações diferenciadas, considerando as referidas áreas, o que leva a inferir que a heterogeneidade em termos de tamanho (população e arrecadação) pode não ser um fator determinante na observância dos limites legais.

Palavras chave: Gasto público. Lei da Responsabilidade Fiscal. Constituição Federal

1 Possui graduação em Ciências Contábeis pela Universidade Federal de Santa Maria, UFSM, e especialização em Gestão Pública Municipal pela Univerisdade Federal de Santa Maria, UFSM. Santa Maria. Rio Grande do Sul. Brasil. E-mail: risberlt@yahoo.com.br

2 Possui graduação em Ciências Econômicas pela Universidade de Santa Cruz do Sul, mestrado em Economia do Desenvolvimento pela Pontifícia Universidade Católica do Rio Grande do Sul e Doutorado em Economia Aplicada pela Universidade Federal de Viçosa. Atualmente é professor adjunto da Universidade Federal de Santa Maria. Santa Maria. Rio Grande do Sul. Brasil. E-mail: reisolibender@yahoo.com.br 3 Possui graduação em Administração de Empresas pela Universidade Federal do Pampa e mestrado em andamento em Administração de Empresas pela Universidade Federal de Santa Maria, UFSM. Santa Maria. Rio Grande do Sul. Brasil. E-mail: pamela_tristao@yahoo.com.br 


\begin{abstract}
Planning and public spending control are one of the most important parts of the new regime in public administration. In this context, the objective of this work is to analyze the limits established by the Fiscal Responsibility Law (LRF) and Federal Constitution at COREDE Alto Jacui from 2005 to 2008. The analyses have indicated that the LRF is not being applied in all the cities in this study due to the fact that the ordinary and integral legal limits established have not been applied. Furthermore, it could be observed that the value spent with salaries has grown continually during the period analyzed, mainly in cities with less population and economically smaller. Although the limits invested in education and health are according to the percentage in law, the majority of the cities in this study have shown contrasting results, and many cities with similar structure have had different results considering the areas studied, leading to the conclusion that heterogeneity in terms of size (populations and taxes collected) may be not a determinant observed factor in the legal limits.
\end{abstract}

Keywords: Public Spending; Fiscal Responsibility Law; Federal Constitution

\title{
1 INTRODUÇÃO
}

Com os avanços econômicos e legais, datados dos anos de 1990, a complexidade dos estudos na área de contabilidade pública vem ganhando espaço. Entre outros aspectos, por levar em consideração as atribuições do setor público, com o objetivo de melhor atender e administrar as reivindicações da sociedade e, ao mesmo tempo, reestruturar as condições financeiras e administrativas, exigidas cada vez com maior intensidade pelos órgãos de fiscalização. Esses avanços também têm repercutido na sociedade brasileira, pela exigência de transparência e responsabilidade no uso dos recursos públicos, postos à disposição de seus representantes, os quais devem ser revertidos em benefícios à sociedade, conforme discutem Ribeiro Filho et al.(2010).

Nesse contexto, as mudanças ocorridas na Administração Pública, por meio da Reforma do Estado Brasileiro, viabilizou um maior enfoque nos resultados (RIBEIRO FILHO et al., 2010). Entretanto, a contabilidade pública ainda não está nos níveis de desenvolvimento de outras áreas; porém, sua importância expande-se por abranger praticamente todas as áreas envolvidas com previsão e execução orçamentária, por meio de registros contábeis, elaboração dos relatórios financeiros, econômicos, patrimoniais e no controle interno, ajudando a administração na tomada de decisões.

Nesse sentido, a partir do surgimento da Lei de Responsabilidade Fiscal (LRF), instituída pela Lei Complementar 101/2000, a contabilidade pública tem estado presente nas discussões acerca do debate público. Por meio dessa Lei, o Brasil passou a utilizar um novo sistema para o regime de administração pública, conhecido como Regime de Gestão Fiscal Responsável, o qual está fixado em três pilares, quais sejam: o planejamento, a transparência e o controle das contas públicas. A partir da referida Lei, a transparência nas contas públicas é obrigatória para os governantes, algo que deveria ser desnecessário, pois o dever de prestar contas de forma transparente é da própria natureza do ato de administrar recursos alheios (LRF, 2000).

Buscando atender a esse propósito, a Lei de Responsabilidade Fiscal foi elaborada pelo Poder Executivo e encontra respaldo no artigo 165, §/9o da Constituição Federal. Ela foi instituída para regulamentar as contas públicas, visando estabelecer um maior equilíbrio entre as receitas e as despesas, assegurando, assim, uma gestão mais transparente e responsável no uso dos recursos governamentais com prioridade para o orçamento, o planejamento e o controle da gestão pública.

A partir da LRF, a contabilidade pública passou a ter uma maior influência nos atos e fatos ocorridos na administração. Ao mesmo tempo, a contabilidade passou a auxiliar os gestores no cumprimento da Lei, pois somente através da contabilidade é que os órgãos de direito conseguem ter um 
controle em relação ao seu patrimônio, aos atos da Fazenda e às suas variações. Associada à Lei de Responsabilidade Fiscal, a Lei Complementar no. 101 estabelece limites em relação aos atos da administração pública e dos entes federativos, particularmente para os gastos com pessoal, despesas previdenciárias, reserva de contingência e dívida consolidada, sendo utilizada a Receita Corrente Líquida (RCL) como parâmetro para a aferição dos limites estabelecidos. A mesma Lei visa contribuir para que haja um equilíbrio em relação às contas públicas, além de uma maior transparência na divulgação de documentos e a aplicação correta dos recursos públicos destinados aos municípios.

No entanto, ao refletir sobre a trajetória da administração pública nos órgãos governamentais, tem-se um histórico de descasos com a sociedade, juntamente com a ineficiência na aplicação dos recursos públicos, por parte das unidades administrativas, seja união, estados ou municípios. Não obstante, apesar das mudanças ocorridas, este aspecto ainda permanece marcante no cenário público do país.

Com isso, associadas às mudanças na legislação pública, s transformações ocorridas tanto nos aspectos econômicos quanto políticos sugerem a necessidade de maior prestação de contas à sociedade e maior clareza na administração pública.

Nesse tocante, aos gastos definidos pela LRF, parte importante destina-se à educação e saúde. Conforme disposto pela Constituição Federal, é acordado o percentual mínimo que a união, os estados, o distrito federal e municípios devem aplicar em educação e saúde. De posse disso, fica estipulado que o gasto dos municípios com saúde deve atingir no mínimo $15 \%$ da sua receita com impostos, e o percentual mínimo de $25 \%$ deve ser aplicado em educação.

Considerando os aspectos discutidos, em âmbito municipal, para que a Lei de Responsabilidade Fiscal tenha uma aplicação mais adequada e para uma melhor fiscalização, os municípios do Estado do Rio Grande do Sul foram divididos por regiões, denominados de Conselhos Regionais de Desenvolvimento (Coredes). Bandeira (2006) complementa, dizendo que esses conselhos têm como finalidade principal possibilitar a participação da sociedade na formulação e na implantação de iniciativas de promoção do desenvolvimento regional. Dentre esses conselhos, está o Corede Alto Jacuí, que atualmente é composto por quatorze municípios, os quais têm uma finalidade comum: administrar com responsabilidade e transparência os recursos públicos para o bem comum da sociedade.

Nesse sentido, este estudo tem como objetivo central analisar a adequação à Lei de Responsabilidade Fiscal e ao cumprimento da Constituição Federal, pelos municípios do Corede Alto Jacuí, na gestão administrativa 2005-2008. Particularmente, busca-se verificar o cumprimento dos percentuais estabelecido em lei quanto às despesas com pessoal e gastos com educação e saúde. $O$ período examinado refere-se a uma gestão administrativa e, quando desenvolvido o presente texto, esses anos compreendiam a última gestão completa. Ademais, para uma análise mais adequada, faz-se necessária a avaliação de uma gestão em sua totalidade, haja vista que a aplicação da Lei está baseada, entre outros aspectos, no princípio da anualidade.

A contribuição do trabalho está em retratar a realidade dos municípios da região do Alto Jacuí, Corede, que apresenta elevada heterogeneidade entre seus municípios, possibilitando a comparação e a análise da administração pública de cada município e verificação quanto ao cumprimento da legislação vigente sobre as contas públicas. Ademais, o trabalho permite, ainda que de forma complementar, analisar e comparar os municípios do Corede Alto Jacuí quanto ao tamanho e à arrecadação.

O trabalho está estruturado em seis seções. Na primeira, é apresentada a introdução; na segunda, encontra-se o embasamento teórico e legal disposto pela Lei de Responsabilidade Fiscal e pela Constituição Federal; a terceira traz a contextualização do Corede Alto Jacuí; a quarta apresenta a metodologia; na quinta, são expostos e discutidos os resultados, e; na sexta, são delineadas as principais conclusões acerca do tema desenvolvido. 


\section{ORÇAMENTO PÚBLICO E LEI DE RESPONSABILIDADE FISCAL}

\subsection{Administração pública}

A gestão pública está relacionada aos interesses da sociedade, sendo que os serviços públicos estão à disposição dos cidadãos. A administração pública pode ser conceituada como um aparelhamento, preordenado à realização de seus serviços, visando à satisfação das necessidades coletivas (MEIRELLES, 1984). Para Mello (1979), administrar é gerir os serviços públicos, o que significa não só prestar serviços como também dirigir, governar, exercer a vontade com objetivo de obter um resultado útil. Corroborando, Carvalho, Abreu e Pedrozo (2013) afirmam que a administração pública tem por finalidade a realização de serviços públicos em prol de todos os cidadãos, tendo por objetivo, dessa forma, a promoção do bem comum.

Administração pública, em sentido objetivo, "abrange as atividades exercidas pelas pessoas jurídicas, órgãos e agentes incumbidos de atender concretamente as necessidades coletivas; corresponde à função administrativa, atribuída preferencialmente aos órgãos do Poder Executivo" (PIETRO, 1998, p.53).

É por meio da administração pública que os governantes podem captar recursos diretos ou indiretos. Para Kohama (2003), pode-se definir administração direta ou centralizada como todos os serviços integrados na estrutura administrativa da Presidência da República e dos Ministérios, no âmbito federal, e do Gabinete do Governador e Secretarias de Estado, no âmbito estadual, e, na administração municipal, deve seguir uma estrutura semelhante. Embora a administração direta seja serviço cuja competência para decidir sobre ele esteja distribuída entre diferentes unidades, estas, devido à relação hierárquica, prendem-se sempre às unidades superiores, num afunilamento crescente e contínuo, chegando, como estreitamento final, sob o comando último do Chefe do Executivo (MELLO, 1979).

Já a administração indireta, que dispõe de um Decreto - Lei Federal no. 200/67, alterado pelo Decreto-Lei Federal no. 900/67 e descentralizada pelo Decreto-Lei complementar do Estado de São Paulo no. 7/69 contempla uma série de entidades, quer de direito público (autarquias), quer de direito privado (empresas públicas, sociedades de economia mista e fundações), por meio da qual o Estado pode descentralizar os serviços públicos ou de interesse público.

\subsection{Contabilidade Pública e orçamento público}

As normas de contabilidade aplicadas ao setor público estão dentro dos padrões da contabilidade brasileira e internacional, e tudo isso se deve ao fato de que as informações necessitam ter clareza e transparência em seus dados para que assim haja uma fácil compreensão. Segundo Pietro (1998), a contabilidade pública é um dos ramos da contabilidade geral aplicada às entidades de direito público interno.

Na contabilidade pública, registra-se a previsão da receita e a fixação da despesa, estabelecidas no Orçamento Público aprovado para o exercício, o qual faz a comparação entre a previsão e a realização das receitas e despesas, controla as operações de crédito, a dívida ativa, os créditos e obrigações, releva as variações patrimoniais e mostra o valor do patrimônio (SLOMSKI, 2003).

No que se pode citar de legislação em relação à contabilidade pública, ela está baseada na Lei 4.320/64 e no cumprimento da Lei Complementar 101/2000. Alguns autores como Slomski (2003) ainda destacam que a contabilidade pública está dividida em quatro sistemas, sendo eles: 
o Orçamentário, o Financeiro, o Patrimonial e o de Competência. Resumidamente, eles compreendem o Sistema Orçamentário, que evidencia o registro contábil da receita e da despesa, no final do exercício, apresenta uma comparação entre a previsão e a execução orçamentária; o Sistema Financeiro, que engloba todas as operações que resultem débitos e créditos de natureza financeira, as quais serão objeto de registro e controle contábil, apresentando, no final do exercício, o resultado financeiro apurado; o Sistema Patrimonial, que registra todos os bens móveis e imóveis da entidade, apresentando, no final do exercício, o resultado da gestão econômica, e o Sistema de Compensação, que registra e movimenta as contas representativas de direitos e obrigações, geralmente decorrentes de contratos, convênios e ajustes, sendo que, quando forem elaborados os balanços, no final do exercício, os saldos de suas contas serão incluídos no Balanço do Sistema Patrimonial.

\subsection{Lei de Responsabilidade Fiscal - LRF}

Com o objetivo de redução e maior controle das despesas públicas, em 04 de maio de 2000 foi editada a Lei Complementar no. 101, denominada Lei de Responsabilidade Fiscal (LRF), a qual tem como pressuposição a ação planejada e transparente das contas públicas, por meio do estabelecimento de normas voltadas à responsabilidade na gestão fiscal dos recursos públicos. Logo, após a implementação, os gastos devem ser feitos de acordo com os limites que estabelece a Lei.

Contudo, a LRF não substitui ou revoga a Lei no $4.320 / 64$, que normatiza as finanças públicas no país há mais de 36 anos. No entanto, impõe a ela várias alterações e releituras. Embora a Constituição Federal tenha determinado a edição de uma nova lei dispondo sobre esse assunto, tal providência ainda carece de conclusão. Porém, já existem no Congresso Nacional alguns projetos de lei em discussão e cuja aprovação levará algum tempo, visto tratar-se de tema complexo, que exige estudos aprofundados, além de vontade política para superar o intrínseco conflito federativo e institucional, pressupostos para sua concretização.

Em pormenores, a Lei estabeleceu limites para as despesas com pessoal, o que é entendido como o somatório dos gastos do ente da Federação com os ativos, inativos e os pensionistas, relativos a mandatos, cargos, funções ou empregos, sejam eles civis, militares ou de qualquer outra espécie remuneratória. A LRF estabeleceu os limites para os gastos como participação da Receita Corrente Líquida de $50 \%$ para a união; $60 \%$ para os estados e o distrito federal, e; $60 \%$ para os municípios. Nestes termos, por Receita Corrente Líquida entende-se o somatório das receitas tributárias, de contribuições patrimoniais, industriais, agropecuárias, de serviços, transferências correntes e outras receitas correntes. Ademais, estabeleceu-se também a partição dos limites das despesas com pessoal para cada poder. Os limites, considerando o ente e os respectivos poderes, encontram-se dispostos na Figura 1.

Figura 1 - Partição dos limites com despesa de pessoal em cada poder e ente da Federação, em \% da Receita Corrente Líquida

\begin{tabular}{cccc}
\hline Poder & União & Estados & Municípios \\
\hline Executivo & 40,9 & 49,0 & 54,0 \\
Legislativo & 2,5 & 3,0 & 6,0 \\
Judiciário & 6,0 & 6,0 & - \\
Ministério Público & 0,6 & 2,0 & - \\
\hline Total & 50,0 & 60,0 & 60,0 \\
\hline
\end{tabular}

Fonte: LRF, 2013 
Porém, a referida Lei não se restringiu aos gastos com pessoal, incluindo também a dívida, para a qual nenhum governante pode criar uma nova despesa continuada (por mais de dois anos) sem indicar necessariamente sua fonte de receita ou sem reduzir outras despesas já existentes. Os limites foram estabelecidos como percentuais das receitas da união, dos estados, do distrito federal e dos municípios.

De acordo com Khair (2001), o surgimento da LRF trouxe vantagens à administração pública, tais como transparência na gestão, maior eficiência na ação governamental, racionalização das despesas, crescimento das receitas, planejamento da ação do governo e herança fiscal. Nesse sentido, a Lei de Responsabilidade Fiscal vem preenchendo importantes lacunas para a obtenção do equilíbrio fiscal do país, ao estabelecer regras claras para a adequação de despesas e dívidas públicas em níveis compatíveis com as receitas de cada ente da Federação. Constitui-se num marco da história das finanças públicas do país. Além disso, a Lei também permite melhor avaliação da gestão de prefeitos, de presidentes da República e de governadores de Estados, ao reduzir fortemente o passivo financeiro que poderia ser repassado ao sucessor.

Além de determinar o limite legal de gastos com pessoal em relação à Receita Corrente Líquida, a LRF ainda atua controlando o limite de gastos com pessoal através do limite prudencial e de alerta. Ambos são considerados medidas de precaução, para que não sejam excedidos os percentuais estipulados para gasto neste segmento.

Definido no art. 22 da LRF, o limite prudencial baseia-se na premissa de medidas corretivas quando o percentual do limite for igual ou superior a $95 \%$ do limite máximo permitido.

Caso esse percentual seja ultrapassado, é vedado ao poder ou órgão:

I. concessão de vantagem, aumento, reajuste ou adequação de remuneração a qualquer título, salvo os derivados de sentença judicial ou de determinação legal ou contratual, ressalvada a revisão prevista no inciso X do art. 37 da Constituição;

II. criação de cargo, emprego ou função;

III. alteração de estrutura de carreira que implique aumento de despesa;

IV. provimento de cargo público, admissão ou contratação de pessoal a qualquer título, ressalvada a reposição decorrente de aposentadoria ou falecimento de servidores das áreas de educação, saúde e segurança;

V. contratação de hora extra, salvo no caso do disposto no inciso II do § 60 do art. 57 da Constituição e as situações previstas na lei de diretrizes orçamentárias.

No que tange ao limite de alerta, é apenas um aviso feito pelos Tribunais de Contas aos entes que alcançarem $90 \%$ do limite máximo, não estando associado a nenhuma penalidade, pois é utilizado para chamar a atenção e orientar o ente a tomar providências que contenham e corrijam despesas, à medida que o limite prudencial e o limite máximo estejam muito próximos, de forma a não ultrapassar os limites estipulados. Ao atingir o limite prudencial, o administrador público poderá tomar medidas de ajuste com o intuito de não ser punido.

Em situações onde os limites estipulados de gastos forem excedidos, é papel de o gestor público adotar medidas para alcançar os limites estabelecidos. As possíveis medidas, ao se ultrapassar os limites para o enquadramento no valor gasto estipulado, consistem no corte do percentual excedente nos dois quadrimestres seguintes, sendo que um terço deve ser reduzido no primeiro quadrimestre seguinte, e o restante adequado nos próximos meses. Caso o município não se enquadre nos meses subsequentes, ele será penalizado de acordo com as sanções previstas em Lei, acarretando em uma multa de $30 \%$ do seu subsídio anual, além do cancelamento no recebimento de transferências voluntárias da União para o município. 
Os instrumentos preconizados pela Lei de Responsabilidade Fiscal para o planejamento público são os mesmos adotados pela Constituição Federal, quais sejam, o Plano Plurianual (PPA), a Lei de Diretrizes orçamentárias (LDO) e a Lei Orçamentária Anual (LOA), as quais são discutidas com mais detalhes nas subseções seguintes.

\subsection{Plano Plurianual - PPA}

O primeiro Plano Plurianual a ser desenvolvido cumprindo as determinações da Constituição de 1988 foi o Quinquênio (1991/1995), mais voltado à programação da ação governamental. De acordo com Kohama (2003), o Plano Plurianual é de médio prazo. Através dele, procura-se ordenar e orientar as ações do governo que levem ao atingimento dos objetivos e metas fixadas para um período de quatro anos, no nível dos governos estaduais e municipais.

Embora existam na Constituição Federal dispositivos a serem observados em relação à elaboração do Plano Plurianual, há citações que remetem o assunto à lei complementar, conforme o § 9o, inciso I, do artigo 165 da Constituição Federal, que diz: I - "dispor sobre o exercício financeiro, a vigência, os prazos, a elaboração e a organização do plano plurianual, da lei de diretrizes orçamentárias e da lei orçamentária anual".

De acordo com Giacomoni (2009), o PPA compreende estratégias, sendo as duas últimas incluídas por meio da Lei de Diretrizes Orçamentárias (LDO):

- consolidar a estabilidade econômica com crescimento sustentável;

- promover o desenvolvimento sustentável, voltado para a geração de empregos;

- combater a pobreza e promover a cidadania e inclusão social;

- consolidar a democracia e a defesa dos direitos humanos;

- reduzir as desigualdades inter-regionais, e;

- promover os direitos de minorias vítimas de preconceitos e discriminação.

\subsection{Lei de Diretrizes Orçamentárias - LDO}

A Lei de Diretrizes Orçamentárias compreende metas e prioridades da administração pública, incluindo as despesas de capital para o exercício financeiro subsequente, orienta a elaboração da lei orçamentária anual, colocada sobre as alterações na legislação tributária e estabelece a política de aplicação das agências financeiras oficiais de fomento (CONSTITUIÇÃO FEDERAL, 1988).

Com a vigência da LRF, cabe à Lei de Diretrizes Orçamentárias, de acordo com seu art. 4ำ, dispor o que rege o $\S 2$ 을 do art. 165 da Constituição Federal e ainda disporá sobre:

- equilíbrio entre receitas e despesas;

- critérios e forma de limitação de empenho, a ser efetivada nas hipóteses previstas no art. 9o e no inciso § 10 do art.3;

- normas relativas ao controle de custos e à avaliação dos resultados dos programas financeiros com recursos do orçamento;

- demais condições e exigências para a transparência de recursos a entidades públicas privadas.

Conforme Giacomoni (2009), o Poder Executivo elabora a LDO e encaminha ao Poder Legislativo, o qual aprova e estabelece as prioridades, as metas fiscais e orienta a proposta orçamen- 
tária. A Lei de Diretrizes Orçamentárias também possui prazos para que seja encaminhada. Em até oito meses e meio antes do encerramento do exercício, a Lei é aprovada em tempo de cumprir sua principal função, que é a de orientar a elaboração da LOA. (CONSTITUICAO FEDERAL, 1988).

\subsection{Lei Orçamentária Anual - LOA}

O projeto de Lei Orçamentária Anual é elaborado de forma compatível com o Plano Plurianual de Investimentos (PPA) e com a Lei de Diretrizes Orçamentárias (LDO). Por meio dela é que são programadas as ações a serem executadas (KOHAMA, 2003). Entretanto, a Lei de Responsabilidade Fiscal ainda dispõe de alguns itens que devem ser observados na elaboração do projeto de Lei Orçamentária Anual, como segue (Artigo 5으, da Lei Complementar no 101/2000):

- Deve estar compatível com o Plano Plurianual e com a Lei Diretrizes Orçamentárias;

- deve conter demonstrativos da compatibilidade da programação com os objetivos e metas constantes do Anexo de Metas Fiscais da LDO;

- será acompanhada de demonstrativo do efeito sobre as receitas e despesas, decorrentes de isenções, anistias, remissões, subsídios e benefícios de natureza financeira, tributária e creditícia, bem como das medidas de compensação à renúncia de receitas e ao aumento de despesas obrigatórias de caráter continuado;

- deve conter reserva de contingência, que pode ser calculada utilizando-se percentual sobre a receita corrente líquida destinada ao atendimento de passivos contingentes e outros riscos e eventos fiscais imprevistos;

- deve constar separadamente toda a despesa relativa à dívida pública na lei orçamentária, e as receitas que as atenderão constarão na LOA;

- é vedado consignar, na lei orçamentária, crédito com finalidade imprecisa ou com dotação ilimitada;

- não consignará dotação para investimento com duração superior a um exercício financeiro que não esteja previsto no plano plurianual ou em lei que autorize a sua inclusão.

A LOA também compreende o orçamento fiscal, o orçamento de investimento das empresas e o orçamento da seguridade social. Integram as despesas da União e são incluídas na lei orçamentária as do Banco Central do Brasil relativas a pessoal e encargos sociais, custeio administrativo, inclusive os destinados a benefícios e assistência aos servidores e a investimentos.

O resultado do Banco Central do Brasil, apurado após a constituição ou reversão de reservas, constitui receita do Tesouro Nacional e será transferido até o décimo dia útil subsequente à aprovação dos balanços semestrais. Já o resultado negativo constituirá obrigação do Tesouro para com o Banco Central do Brasil e será consignado em dotação específica no orçamento.

\subsection{A Constituição Federal}

Considerada um conjunto de regras de governo que regem o ordenamento jurídico de um país, a Constituição Federal ou Carta Constitucional em vigor atualmente foi promulgada em 05 de outubro de 1988, através da aprovação de uma Assembleia Constituinte, formada por deputados e senadores. Este ato marcou o início da consolidação da democracia e, logo em seguida, nos anos 90 , foi eleito diretamente pelo povo o primeiro presidente do país. 
A Constituição deve regular e pacificar os conflitos e interesses de grupos que integram a sociedade, estabelecendo regras que tratem desde os direitos fundamentais do cidadão até a organização dos Poderes, defesa do Estado e da Democracia, seja em âmbito econômico ou social.

Das leis e obrigações estipuladas pela Constituição, pode-se citar a Lei de Responsabilidade Fiscal - LRF, a qual determina uma administração mais transparente dos municípios pelos gestores, além disso, estabelece - baseado no recolhimento de impostos do município, o percentual a ser gasto com saúde e educação.

No que tange aos gastos com saúde, A Lei Complementar no 141 de 13 de janeiro de 2012 apresenta os valores mínimos a serem aplicados anualmente por união, estados, distrito federal e municípios em ações e serviços públicos de saúde. Da mesma forma, estabelece os critérios usados para rateio dos recursos para saúde e normas de fiscalização, avaliação e controle das despesas com esta. No que se refere à aplicação dos recursos em saúde, é estabelecido, no capítulo III Art. 60, que os estados e o distrito federal devem aplicar no mínimo $12 \%$ do valor arrecadado com impostos em ações e serviços públicos de saúde. Aos municípios, o percentual estipulado para gastos relacionados à saúde é de, no mínimo, 15\% do total de impostos arrecadados.

Quanto à educação, são igualmente determinados os percentuais mínimos a serem investidos. Conforme Art. 212 da Constituição Federal fica estabelecido que a união deverá aplicar no mínimo $18 \%$ do resultante dos impostos com educação nos estados, no entanto, ao distrito federal e estados cabe o investimento de no mínimo $25 \%$ da receita com impostos e arrecadações.

\section{CONTEXTUALIZAÇÃO DO COREDE ALTO JACUÍ}

O Conselho Regional de Desenvolvimento (Corede) é um órgão que tem como objetivo a discussão e o levantamento de questões de políticas e ações que visam ao desenvolvimento regional. O COREDE foi criado por meio da Lei Estadual $n^{\circ} 10.283$, de 17 de outubro de 1994. De acordo com o art. $2^{\circ}$, o Corede tem como objetivo a promoção do desenvolvimento regional, harmônico e sustentável; através da integração dos recursos e das ações do governo na região, visando à melhoria da qualidade de vida da população, à distribuição equitativa da riqueza produzida, ao estímulo à permanência do homem em sua região e à preservação e recuperação do meio ambiente (BANDEIRA, 2006).

O Estado do Rio Grande do Sul está dividido em vinte o oito COREDES, sendo um deles o Corede Alto Jacuí, o qual é composto por quatorze municípios, sendo eles: Boa Vista do Cadeado, Boa Vista do Incra, Colorado, Cruz Alta, Fortaleza dos Valos, Ibirubá, Lagoa dos Três Cantos, Não-Me-Toque, Quinze de Novembro, Saldanha Marinho, Salto do Jacuí, Santa Bárbara do Sul, Selbach e Tapera, sendo os quatorze localizados no Noroeste do Estado do Rio Grande do Sul.

De acordo com Santos e Pompeo (2005), a economia dessa região está embasada fortemente na agropecuária, destacando-se as atividades de produção de soja, milho e trigo, e também na criação de bovinos de carne e suínos e na pecuária leiteira. Na região existem, de acordo com dados do IBGE (2011), 17.607 estabelecimentos rurais, dos quais $77,85 \%$ são pequenas propriedades, com extensão de até 50 hectares, as propriedades de médio porte representam 20,23\%, com extensão de 51 até 500 hectares e os estabelecimentos com mais de 500 hectares correspondem a $1,92 \%$.

Pode-se destacar também que a região é responsável por cerca de $65 \%$ da energia gerada no Estado Rio Grande do Sul devido ao complexo hidrelétrico constituído pelas usinas localizadas no município de Salto do Jacuí, a Usina Leonel de Moura Brizola, a Usina do Alagado do Passo Real e a Usina de Itaúba. 
Entre avanços e recuos, em 1994, os Coredes foram criados oficialmente por meio da Lei 10.283 de 17 de outubro de 1994, que, em seu artigo 3o, estabelecia as competências desses conselhos.

Art. 3o - Competem aos Conselhos Regionais de Desenvolvimento, dentre outras, as seguintes atribuições:

I - promover a participação de todos os segmentos da sociedade regional no diagnóstico de suas necessidades e potencialidades, para a formulação e implementação das políticas de desenvolvimento integrado da região;

II - elaborar planos estratégicos de desenvolvimento regional;

III - manter espaço permanente de participação democrática, resgatando a cidadania, através da valorização da ação política;

IV - constituir-se em instância de regionalização do orçamento do Estado, conforme estabelece o artigo 149, parágrafo 8으, da Constituição do Estado;

$\mathrm{V}$ - orientar e acompanhar, de forma sistemática, o desempenho das ações dos governos Estadual e Federal na região;

VI - respaldar as ações do Governo do Estado na busca de maior participação nas decisões nacionais.

Em síntese, os municípios que compõem o Corede Alto Jacuí, em sua grande maioria, possuem receitas oriundas da atividade agrícola. Segundo dados do IBGE (2011), $72 \%$ do território do Corede é ocupado por plantações de soja e trigo, sendo assim, as receitas com tributos dos municípios são, em grande medida, geradas pela atividade agrícola. Logo, a área cultivada e agriculturável é fator determinante nos municípios da região, ainda mais devido ao expressivo diferencial em termos de extensão territorial.

Tabela 1 - Dados socioeconômicos do Corede Alto Jacuí

\begin{tabular}{ccccc}
\hline Município & $\begin{array}{c}\text { População } \\
(2011)\end{array}$ & $\begin{array}{c}\text { Área } \\
(2011)\end{array}$ & $\begin{array}{c}\text { PIBpm } \\
(2009)\end{array}$ & $\begin{array}{c}\text { PIB per capita } \\
\text { (2009) }\end{array}$ \\
\hline Boa vista do Cadeado & 2.440 & $701,1 \mathrm{~km}^{2}$ & $87.853 \mathrm{mil}$ & $34.793 \mathrm{mil}$ \\
Boa Vista do Incra & 2.436 & $503,5 \mathrm{~km}^{2}$ & $73.121 \mathrm{mil}$ & $28.309 \mathrm{mil}$ \\
Colorado & 3.527 & $286,2 \mathrm{~km}^{2}$ & $92.533 \mathrm{mil}$ & $24.538 \mathrm{mil}$ \\
Cruz Alta & 62.776 & $1.360,4 \mathrm{~km}^{2}$ & $1.524 .519 \mathrm{mil}$ & $23.659 \mathrm{mil}$ \\
Fortaleza dos Valos & 4.566 & $650,3 \mathrm{~km}^{2}$ & $123.020 \mathrm{mil}$ & $26.542 \mathrm{mil}$ \\
Ibirubá & 19.365 & $611,8 \mathrm{~km}^{2}$ & $548.264 \mathrm{mil}$ & $28.322 \mathrm{mil}$ \\
Lagoa dos Três Cantos & 1.595 & $138,6 \mathrm{~km}^{2}$ & $42.163 \mathrm{mil}$ & $25.819 \mathrm{mil}$ \\
Não-Me-Toque & 16.025 & $361,7 \mathrm{~km}^{2}$ & $439.259 \mathrm{mil}$ & $27.433 \mathrm{mil}$ \\
XV de Novembro & 3.657 & $223,6 \mathrm{~km}^{2}$ & $78.386 \mathrm{mil}$ & $21.312 \mathrm{mil}$ \\
Saldanha Marinho & 2.856 & $221,6 \mathrm{~km}^{2}$ & $72.683 \mathrm{mil}$ & $24.075 \mathrm{mil}$ \\
Salto do Jacuí & 11.927 & $519,2 \mathrm{~km}^{2}$ & $183.266 \mathrm{mil}$ & $14.351 \mathrm{mil}$ \\
Santa Barbara do Sul & 8.795 & $971,2 \mathrm{~km}^{2}$ & $269.984 \mathrm{mil}$ & $29.461 \mathrm{mil}$ \\
Selbach & 4.933 & $176,7 \mathrm{~km}^{2}$ & $96.667 \mathrm{mil}$ & $19.680 \mathrm{mil}$ \\
Tapera & 10.459 & $179,6 \mathrm{~km}^{2}$ & $243.323 \mathrm{mil}$ & $22.557 \mathrm{mil}$ \\
\hline
\end{tabular}

Fonte: FEEDADOS, 2012.

A heterogeneidade dos municípios do COREDE evidencia-se também pelos diferenciais de renda, uma vez que o maior PIB per capita (do município de Boa Vista do Cadeado) foi uma vez e meia o PIB per capita do município de Salto do Jacuí, o de menor renda em 2009. Contudo, Salto do Jacuí possui população quase quatro vezes maior que a do município de Boa Vista do Cadeado. 


\section{PROCEDIMENTOS METODOLÓGICOS}

A apresentação da metodologia está estruturada em três etapas. A primeira contextualiza a pesquisa, definindo o método e os objetivos, enquanto que as demais definem os procedimentos quantitativos. Dessa forma, o trabalho utiliza tanto a abordagem qualitativa quanto a quantitativa, compreendendo um estudo analítico e descritivo. É analítico porque envolve o estudo e avaliação aprofundados de informações disponíveis na tentativa de explicar o contexto de um fenômeno e descritivo porque visa ao conhecimento do comportamento, gerando pesquisas que permitam a compreensão das razões determinantes de certas realidades observadas, de modo a visualizar um campo mais amplo de observação (ver Munhoz, 1989).

Para isso, inicialmente foi realizado um levantamento, por meio de textos específicos e da legislação pertinente, de aspectos que constituíram a primeira etapa e contemplam as três seções iniciais do texto, respectivamente. Na segunda etapa, foram realizados comparativos entre os valores estabelecidos pela Lei de Responsabilidade Fiscal e o executado pelos municípios do Corede Alto Jacuí com a finalidade específica de examinar a observância dos limites definidos pela referida Lei. Em seguida, na terceira etapa, analisaram-se os gastos com saúde e educação em relação aos limites estabelecidos pela Constituição Federal em cada um dos municípios do respectivo Corede.

Para atingir esses objetivos, foram coletados dados dos relatórios contábeis de cada um dos municípios integrantes do Corede Alto Jacuí, os quais estão disponíveis no sítio do Tribunal de Contas do Estado do Rio Grande do Sul (TCE/RS). As variáveis utilizadas bem como também suas definições encontram-se na Tabela 2. Os dados têm periocidade anual, estão em valores correntes e em milhões de reais.

Tabela 2 - Variáveis utilizadas

\begin{tabular}{ccccc}
\hline Variável & Periodic. & Unidade Monetária R\$ & Fonte & Período \\
\hline Receita Corrente Líquida & Anual & Milhões & Feedados & 2005 a 2008 \\
Desp. Pessoal & Anual & Milhões & Feedados & 2005 a 2008 \\
Desp. Saúde & Anual & Milhões & Feedados & 2005 a 2008 \\
Desp. Educação & Anual & Milhões & Feedados & 2005 a 2008 \\
\hline
\end{tabular}

Fonte: FEEDADOS, 2012.

Como os valores estão expressos em moeda corrente, para obter o percentual gasto com pessoal do executivo, com educação e com saúde e, posteriormente, comparar com os limites estabelecidos pelas leis - LRF e Constituição Federal -, fez-se a razão entre o valor bruto da despesa e a receita corrente líquida de cada município em cada um dos respectivos anos analisados. A partir disso, foi possível avaliar temporalmente os resultados orçamentários (gastos) dos municípios com relação aos limites estabelecidos.

\section{RESULTADOS E DISCUSSÕES}

Nesta etapa, são apresentados os resultados da pesquisa. Iniciando a análise, a Tabela 3 apresenta o comparativo entre o que a Lei de Responsabilidade Fiscal estabelece com percentual máximo para gastos com despesa de pessoal e o percentual gasto em cada município estudado. Ressalta-se que foram analisados somente os gastos do Poder Executivo, para o qual a Lei estabelece o limite de $54 \%$ da Receita Corrente Líquida.

De forma geral, os municípios do Corede Alto Jacuí cumpriram o limite estabelecido pela Lei de Responsabilidade Fiscal para as despesas com pessoal; porém, observou-se um crescimento 
das despesas em praticamente todos os municípios, nos três primeiros anos, ao passo que, em 2008, ocorre um movimento contrário. A exceção ficou a cargo do município de Salto do Jacuí, que apresentou gastos crescentes e superiores aos limites estabelecidos em três dos quatro anos analisados, sendo que apenas em 2006 o município estava enquadrado no limite máximo estabelecido.

Essa evidência vai ao encontro do exposto por Menezes (2005), Fioravante, Pinheiro e Vieira (2006) e Giuberti (2006), os quais enfatizaram que a Lei de Responsabilidade Fiscal foi eficaz na redução dos déficits públicos dos municípios, porém a definição do limite em $60 \%$ foi excessivamente majorada, dado que uma minoria dos municípios atingia esse teto. Como consequência, ocorreu um estímulo aos gastos com pessoal em entes (municípios) da federação cujas despesas eram inferiores ao teto.

O município de Salto do Jacuí, por ter excedido o limite prudencial e o teto estabelecido pela Lei, incorrerá em penalidades, sendo vedada, entre outros aspectos, a concessão de vantagem, aumento, criação de cargos ou mesmo a admissão e/ou contratação de pessoal enquanto o ajuste não for realizado e as regras não forem cumpridas. Esse descumprimento pode estar associado ao alto número de funcionários e ao grande número de cargos comissionados.

Os municípios de Colorado, Não-Me-Toque e Tapera não atingiram o limite de gastos, porém, em pelo menos um ano, superaram o limite de alerta, situação que indica que o município gastou mais de $90 \%$, limite máximo. Contudo, esse nível de gasto não implica a ocorrência de penalidade, sendo somente um alerta do Tribunal de Contas. Particularmente, o município de Colorado, que, no ano de 2006 apresentou um gasto com pessoal de 47,10\%, em 2007 e 2008 apresentou uma pequena redução nos percentuais; o município de Não-Me-Toque, no ano de 2007, apresentou percentuais próximos dos $47 \%$, porém, em 2008, a despesa ficou abaixo dos $40 \%$ da Receita Corrente Líquida; já o município de Tapera, em 2006, atingiu o percentual de $46,35 \%$ da despesa com pessoal, retraíndo essa despesa em 2007 e 2008, ficando dentro dos limites exigidos por lei.

Tabela 3 - Despesa total com pessoal do executivo dos municípios do Corede Alto Jacuí, no período entre 2005 e 2008.

\begin{tabular}{c|cc|cc|cc|cc}
\hline \multicolumn{2}{c}{2005} & \multicolumn{2}{c}{$\mathbf{2 0 0 6}$} & \multicolumn{2}{c}{$\mathbf{2 0 0 7}$} & $\mathbf{2 0 0 8}$ \\
\hline Município & Real & Lei \% & $\begin{array}{c}\text { Real } \\
\%\end{array}$ & $\begin{array}{c}\text { Lei } \\
\%\end{array}$ & $\begin{array}{c}\text { Real } \\
\%\end{array}$ & Lei \% & $\begin{array}{c}\text { Real } \\
\%\end{array}$ & $\begin{array}{c}\text { Lei \% } \\
\text { Gasto com Folha }\end{array}$ \\
Boa vista do Cadeado & 21,49 & 54 & 23,13 & 54 & 22,91 & 54 & 20,31 & 54 \\
Boa Vista do Incra & 37,06 & 54 & 38,14 & 54 & 40,38 & 54 & 38,16 & 54 \\
Colorado & 45,50 & 54 & 47,10 & 54 & 46,91 & 54 & 46,76 & 54 \\
Cruz Alta & 40,19 & 54 & 40,10 & 54 & 38,62 & 54 & 43,58 & 54 \\
Fortaleza dos Valos & 41,50 & 54 & 46,88 & 54 & 42,39 & 54 & 40,85 & 54 \\
Ibirubá & 35,22 & 54 & 39,22 & 54 & 39,50 & 54 & 40,45 & 54 \\
Lagoa dos Três Cantos & 30,21 & 54 & 30,48 & 54 & 29,77 & 54 & 28,60 & 54 \\
Não-Me-Toque & 42,39 & 54 & 45,48 & 54 & 46,97 & 54 & 39,15 & 54 \\
XV de Novembro & 37,70 & 54 & 39,20 & 54 & 36,98 & 54 & 34,94 & 54 \\
Saldanha Marinho & 44,38 & 54 & 44,24 & 54 & 44,76 & 54 & 42,60 & 54 \\
Salto do Jacuín & 50,58 & 54 & 67,39 & 54 & 58,13 & 54 & 64,92 & 54 \\
Santa Barbara do Sul & 40,91 & 54 & 45,27 & 54 & 44,62 & 54 & 45,18 & 54 \\
Selbach & 40,36 & 54 & 39,97 & 54 & 40,09 & 54 & 35,91 & 54 \\
Tapera & 43,29 & 54 & 46,35 & 54 & 44,88 & 54 & 36,53 & 54 \\
\hline
\end{tabular}

Fonte: TCE (Tribunal de Contas do Estado) 2012. Adaptada pelos autores

Se relacionados os percentuais destinados ao gasto com pessoal com o total de habitantes dos municípios, pode-se ressaltar que os municípios de Ibirubá e Não-Me-Toque apresentam percentual semelhante às despesas dos municíos de Boa Vista do Cadeado e Boa Vista do Incra, 
os quais possuem as menores populações do Corede. Dessa forma, não é possível afirmar que, quanto maior o município, maior o percentual gasto com pessoal. Embora tenha havido exceções, os menores municípios do Corede apresentaram percentual semelhante ao dos mais populosos. Logo, a heterogeneidade verificada não implicou, nessa região, diferenciais significativos quanto à observância dos limites impostos pela Lei de Responsabilidade Fiscal.

No que tange aos gastos com educação, a Constituição Federal define que cada município deve gastar no mínimo $25 \%$ do total de sua receita com a formação educacional. Buscando verificar a observância desse limite, a Tabela 4 estabelece o comparativo entre a Receita Corrente Líquida (RCL) e o gasto com educação nos municípios do Corede Alto Jacuí, no período de 2005 a 2008.

Tabela 4 - Despesa total com educação dos minicípios do Corede Alto Jacuí, no período entre 2005 e 2008.

\begin{tabular}{|c|c|c|c|c|c|c|c|c|}
\hline \multirow{2}{*}{$\begin{array}{l}\text { Município } \\
\text { Gasto com Folha }\end{array}$} & \multicolumn{2}{|c|}{2005} & \multicolumn{2}{|c|}{2006} & \multicolumn{2}{|c|}{2007} & \multicolumn{2}{|c|}{2008} \\
\hline & $\begin{array}{c}\text { Real. } \\
\%\end{array}$ & Lei \% & $\begin{array}{c}\text { Real. } \\
\%\end{array}$ & $\begin{array}{l}\text { Lei } \\
\%\end{array}$ & $\begin{array}{c}\text { Real. } \\
\%\end{array}$ & Lei \% & $\begin{array}{c}\text { Real. } \\
\%\end{array}$ & Lei \% \\
\hline Boa vista do Cadeado & 19,32 & 25 & 22,50 & 25 & 18,91 & 25 & 13,66 & 25 \\
\hline Boa Vista do Incra & 29,62 & 25 & 31,44 & 25 & 32,22 & 25 & 23,68 & 25 \\
\hline Colorado & 26,10 & 25 & 26,60 & 25 & 28,88 & 25 & 27,32 & 25 \\
\hline Cruz Alta & 28,70 & 25 & 28,31 & 25 & 24,92 & 25 & 28,92 & 25 \\
\hline Fortaleza dos Valos & 23,29 & 25 & 25,35 & 25 & 24,63 & 25 & 23,44 & 25 \\
\hline Ibirubá & 27,54 & 25 & 29,19 & 25 & 28,44 & 25 & 25,39 & 25 \\
\hline Lagoa dos Três Cantos & 25,90 & 25 & 26,51 & 25 & 27,75 & 25 & 12,79 & 25 \\
\hline Não-Me-Toque & 28,99 & 25 & 28,43 & 25 & 31,04 & 25 & 28,67 & 25 \\
\hline XV de Novembro & 26,77 & 25 & 26,77 & 25 & 28,25 & 25 & 17,94 & 25 \\
\hline Saldanha Marinho & 28,80 & 25 & 23,91 & 25 & 23,75 & 25 & 18,81 & 25 \\
\hline Salto do Jacuí & 23,10 & 25 & 30,40 & 25 & 27,60 & 25 & 29,87 & 25 \\
\hline Santa Barbara do Sul & 22,92 & 25 & 23,60 & 25 & 22,67 & 25 & 23,77 & 25 \\
\hline Selbach & 27,15 & 25 & 26,79 & 25 & 28,98 & 25 & 18,72 & 25 \\
\hline Tapera & 26,86 & 25 & 26,49 & 25 & 27,03 & 25 & 20,94 & 25 \\
\hline
\end{tabular}

Fonte: TCE (Tribunal de Contas do Estado) 2012. Adaptada pelos autores

De forma geral, verifica-se que os munícipios do Corede, em sua grande maioria, atenderam ao definido pela Constituição Federal, porém os gastos com educação apresentaram expressivas oscilações nos valores investidos, sendo que, no ano de 2008 , ocorreu redução em praticamente todos os municípios. Se comprados os municípios entre si, observa-se que a volatilidade do gasto ocorre com mais intensidade nos municípios menores (Boa Vista do cadeado, Lagoa dos Três Cantos), contrariamente aos mais populosos, que mantêm um nível de gasto praticamente constante, com pequenas oscilações, caso dos municípios de Cruz Alta, Ibirubá e Não-Me-Toque.

Ademais, observa-se que, nos municípios de Boa vista do Cadeado e de Santa Bárbara do Sul, o investimento em educação foi inferior ao estabelecido pela Constituição Federal em todos os anos analisados. Além desses, o município de Fortaleza dos Valos, nos últimos dois anos, não despendeu recursos suficientes para atingir os percentuais minimos exigidos pela Constituição Federal.

A partir desses resultados, é possível traçar um panorama para os municípios do Corede Alto Jacuí, observando que os menores populacionalmente encontram maiores dificuldades de cumprir os percentuais mínimos referentes à educação. Contrariamente, os municípios maiores apresentaram percentuais médios de gastos próximos de $28 \%$, casos de Não-Me-Toque e Ibirubá. Corroborando com os achados desta pesquisa, Santos e Pompeu (2005) afirmam que os muni- 
cípios de menor arrecadação e menor população têm a necessidade de buscarem ajuda junto aos orgãos públicos e, assim, os gestores têm prioridades e gastos com outras áreas, deixando de cumprir outros percentuais. Corroborando com esta pesquisa, Gerigk e Clemente (2011), em estudo acerca da aplicação da LRF em pequenos municípios paraenses, afirma que municípios com menos de 5 mil habitantes foram afetados pela aplicação da LRF, principalmente no que se refere à dependência de receitas correntes.

Nessa linha, analisaram-se também os gastos com saúde pelos municípos do Corede Alto Jacuí, conforme resultados que se encontram na Tabela 5. Ressalta-se que o percentual mínimo definido pela Consituição Federal para o financiamento com saúde é de $15 \%$ da receita total dos municípios. A partir dos resultados, verificou-se que praticamente todos os municípios investiram o percentual mínimo exigido de $15 \%$ de sua receita total em saúde. Além disso, observou-se que esses gastos apresentaram maior regularidade no período.

A exceção encontra-se nos municípios de Boa Vista do Cadeado, que não cumpriu o estipulado pela Constituição Federal em nenhum dos anos analisados, e Selbach, cujos percentuais gastos em saúde, nos anos de 2005 e 2006, foram inferiores a 15\%, porém, nos anos seguintes, a saúde teve gastos superiores ao mínimo exigido. Por outro lado, o município de Salto do Jacuí apresentou investimentos médios com saúde superiores a $25 \%$ da receita. A grande estrutura do hospital pode ser um dos motivos que possivelmente requerem maiores investimentos do município de Salto do Jacuí.

Tabela 5 - Despesa total com saúde dos minicípios do Corede Alto Jacuí, no período entre 2005 e 2008.

\begin{tabular}{c|ccccccccc}
\hline Município & \multicolumn{2}{c}{$\mathbf{2 0 0 5}$} & \multicolumn{2}{c|}{$\mathbf{2 0 0 6}$} & \multicolumn{2}{c}{$\mathbf{2 0 0 7}$} & \multicolumn{2}{c}{$\mathbf{2 0 0 8}$} \\
\hline Gasto com Folha & $\begin{array}{c}\text { Real. } \\
\%\end{array}$ & Lei $\%$ & $\begin{array}{c}\text { Real. } \\
\%\end{array}$ & $\begin{array}{c}\text { Lei } \\
\%\end{array}$ & $\begin{array}{c}\text { Real. } \\
\%\end{array}$ & Lei \% & $\begin{array}{c}\text { Real. } \\
\%\end{array}$ & Lei \% \\
Boa vista do Cadeado & 11,64 & 15 & 12,80 & 15 & 11,54 & 15 & 11,10 & 15 \\
Boa Vista do Incra & 18,35 & 15 & 19,61 & 15 & 19,93 & 15 & 19,33 & 15 \\
Colorado & 17,27 & 15 & 16,97 & 15 & 17,65 & 15 & 19,17 & 15 \\
Cruz Alta & 17,40 & 15 & 18,76 & 15 & 17,05 & 15 & 18,19 & 15 \\
Fortaleza dos Valos & 16,34 & 15 & 20,06 & 15 & 18,85 & 15 & 18,10 & 15 \\
Ibirubá & 18,11 & 15 & 19,08 & 15 & 20,68 & 15 & 18,83 & 15 \\
Lagoa dos Três Cantos & 19,68 & 15 & 18,38 & 15 & 18,53 & 15 & 18,60 & 15 \\
Não-Me-Toque & 16,42 & 15 & 15,96 & 15 & 16,15 & 15 & 18,84 & 15 \\
XV de Novembro & 16,22 & 15 & 18,20 & 15 & 16,13 & 15 & 16,31 & 15 \\
Saldanha Marinho & 21,77 & 15 & 19,69 & 15 & 19,35 & 15 & 20,23 & 15 \\
Salto do Jacuí & 25,82 & 15 & 27,75 & 15 & 26,25 & 15 & 25,45 & 15 \\
Santa Barbara do Sul & 15,39 & 15 & 19,87 & 15 & 17,47 & 15 & 18,83 & 15 \\
Selbach & 10,90 & 15 & 10,93 & 15 & 16,19 & 15 & 15,94 & 15 \\
Tapera & 20,00 & 15 & 20,93 & 15 & 21,74 & 15 & 19,26 & 15 \\
\hline
\end{tabular}

Fonte: TCE (Tribunal de Contas do Estado) 2012. Adaptada pelos autores

Quando comparados os municípios do COREDE Alto Jacuí em relação à sua população e seus percentuais de investimento em educação, pode-se verificar que não há uma clara diferenciação entre municípios maiores e menores. Isso torná-se mais evidente observando-se os percentuais investidos por Cruz Alta e Não-Me-Toque, os quais apresentaram gastos inferiores aos dos municípios de Lagoa dos Três Cantos, Boa Vista do Incra e Saldanha Marinho. 


\section{CONCLUSÕES}

Por meio das informações levantadas, buscou-se alcançar o objetivo deste estudo, o qual consistiu em analisar de maneira mais aprofundada a situação dos municípios do Corede Alto Jacuí, no que tange ao cumprimento da Lei de Responsabilidade Fiscal e da Consituição Federal, quanto aos gastos com pessoal e ao financiamento das áreas de educação e da saúde.

No que tange à Lei de Responsabilidade Fiscal, esta foi sem dúvida um avanço para os órgãos públicos, auxiliando na questão do gerenciamento e da transparência na gestão dos recursos públicos. Porém, apesar do avanço, não se verificou que a Lei esteja sendo cumprida por todos os municípios do Corede, pois, como foi abordado no decorrer da análise, em alguns municípios, não houve cumprimento ordinário integral dos limites estabelecidos. Outra observação referente aos gastos com pessoal está no crescimente contínuo ao longo do período analisado, o que reflete que os municípios, embora não excedendo o teto, vêm ampliando os gastos com folha de pagamento na administração pública, sobremaneira em municípios menores populacional e economicamente.

O financiamento da educação e da saúde, nos municipíos do Corede Alto Jacuí, apresentou resultados prospectivos ao mesmo tempo contrastantes, sendo que municípios com estrutura semelhante apresentaram situações diferenciadas, considerando as referidas áreas, o que leva a inferir que a heterogeneidade em termos de tamanho (população e arrecadação) pode não ser um fator determinante na observância dos limites legais.

Contudo, quase que integralmente os municípios atenderam aos limites estabelecidos, sendo que os gastos com educação apresentaram menor regularidade, sofrendo alterações mais expressivas de um ano para outro, enquanto que os serviços de saúde foram financiados de forma mais regular pelos municípios. Porém, convém destacar que o financiamento com educação ocorreu de forma mais integral e acima do limite estabelecido inclusive, nos municípios maiores do Corede, ficando os menores investimentos a cargo dos municípios menores, situação que não se verificou no financiamento da saúde, cujos percentuais apresentaram certa similaridade.

Cabe ressalva, que o estudo proposto limitou-se a averiguar a observância legal dos limites estabelecidos pela Lei de Responsabilidade Fiscal e pela Consituição Federal para gastos com pessoal, educação e saúde. Logo, uma análise pormenorizada dos municípios, como também a ampliação do período possibilitaria diagnósticos mais derradeiros acerca da gestão dos recursos públicos pelos municípios do Corede Alto Jacuí. Outro aspecto direciona-se à avaliação da eficiência dos gastos, asepcto que não foi abordado no presente texto e que se consituiu em perspectivas para trabalhos futuros.

\section{REFERÊNCIAS}

BANDEIRA, P. S. Evolução e situação atual dos COREDEs. In: COREDES RS. Fórum dos Conselhos Regionais de Desenvolvimento do Rio Grande do Sul. Pró-RS III, bases para um consenso pró-desenvolvimento regional do Rio Grande do Sul. Porto Alegre: COREDEs, 2006.

BRASIL. Lei Complementar № 101 - Lei de Responsabilidade Fiscal. 04 mai. 2000.
BRASIL. Lei no 4.320 - Lei das Finanças Públicas, 17/mar.1964

BRASIL. Lei Estadual no 10.283, 1994

BRASIL. Lei Federal no 200, 1967.

BRASIL.Constituição Federal, 1988

CARVALHO, A. B.; ABREU, I. M. C.; PREDROZO, I. F. Fluxograma como ferramenta de aperfeiçoamento e de controle em instituições públicas. Revista de Administração da UFSM, v.6, n. 2, p. 373-395, Santa Maria, junho/ 2013 
DI PIETRO, M. S. Z. Direito Administrativo. ga.ed. Editora Altas, 1998.

FUNDAÇÃO DE ECONOMIA E ESTATÍSTICA - FEE. Dados estatisticos, Disponivel em: http://www.fee.rs.gov.br/feedados/consulta/ sel_modulo_pesquisa.asp. Acesso em 25 out. 2012.

FIORAVANTE, D. G.; PINHEIRO, M. M. S.; VIEIRA, R. S. Lei de Responsabilidade Fiscal e finanças públicas municipais: impactos sobre despesas com pessoal e endividamento. Instituito de Pesquisa Econômica Aplicada, 2006. (Texto para Discussão n. 1223)

GERIGK, W.; CLEMENTE, A. Influência da LRF sobre a gestão financeira: espaço de manobra dos municípios paraenses extremamente pequenos. Revista de Administração Contemporânea, vol. 15, n.3, Curitiba, 2011.

GIACOMONI, J. Orçamento Público. 14a. ed., Editora Altas, 2009.

GIUBERTI, A. C. Lei de Responsabilidade Fiscal: efeitos sobre o gasto com pessoal dos municípios brasileiros. Anais do XXXIII ANPEC, 2005.

KHAIR, A. A. Lei de Responsabilidade Fiscal: Guia de orientação para as prefeituras. Ministério do Planejamento, Orçamento e Gestão, 2001. Disponível em: http://www. bndes.gov.br/SiteBNDES/export/sites/default/ bndes_pt/Galerias/Arquivos/conhecimento/ livro_Irf/guia.pdf. Acesso em: 05 ago. 2014.

KOHAMA, H. Contabilidade Pública: Teoria e Prática, 2a.ed. Editora Atlas, 2003.

MEIRELLES, H. L. Direito administrativo brasileiro. Revista das Tribunas.4a.ed. São Paulo: Atlas, 1984.

MELLO, O. A. B. Princípios Gerais de Direito Administrativo. Rio de Janeiro: Forensi, 1979.

MENEZES, R. T. Impactos da Lei de Responsabilidade Fiscal sobre os componentes da despesa dso municípios brasileiros. Brasília: ESAF, 2005. X Prêmio Tesouro Nacional, 2005.

MUNHOZ, D. G. Economia aplicada: técnicas de pesquisa e análise econômica. Brasília: Editora da Universidade de Brasília, 1989.

RIBEIRO FILHO, J. F.; LOPES, J. E. de G.; PEDERNEIRAS, M. M. M.; SILVA, A. J. de M.; MULATINHO, C. E. S. Recomendações em auditoria operacional: Uma prospecção de fragilidades, com base na inteligência competitiva. Revista de Administração da UFSM, v.3, n. 2, p.191-2004, Santa Maria, mai/ ago. 2010 .

SANTOS A. R. L.; POMPEO, S. E. C. Gestão Municipal e Lei de Responsabilidade Fiscal LRF, 2005.

SLOMSKI, V. Manual de Contabilidade Pública: um enfoque na Contabilidade Municipal, 2 $2^{a}$. ed. Editora Altas, 2003. 